\title{
Isolation and Characterization of a Novel Magnetotactic Bacterium From Iran: Iron Uptake and Producing Magnetic Nanoparticles in Alphaproteobacterium MTB-KTN90
}

\author{
Parisa Tajer Mohammad Ghazvini ${ }^{1}$; Rouha Kasra Kermanshahi ${ }^{1,}$; Ahmad Nozad Golikand ${ }^{2}$; \\ Majid Sadeghizadeh ${ }^{3}$ \\ ${ }_{2}^{1}$ Department of Biology, Faculty of Science, Alzahra University, Tehran, IR Iran \\ ${ }_{2}^{2}$ Material Research School, Nuclear Science and Technology Research Institute (NSTRI), Tehran, IR Iran \\ ${ }^{3}$ Department of Genetics, Faculty of Biological Science, Tarbiat Modares University, Tehran, IR Iran \\ *Corresponding author: Rouha Kasra Kermanshahi, Department of Biology, Faculty of Science, Alzahra University, Tehran, IR Iran. Tel: +98-2188044051-53 (2709), Fax: +98-2188058912, \\ E-mail: rkasra@yahoo.com, rkasra@alzahra.ac.ir
}

Received: April 11, 2013; Revised: June 07, 2014; Accepted: June 21, 2014

\begin{abstract}
Background: Magnetotactic bacteria (MTB) have the ability to biomineralize unique intracellular magnetic nanosize particles. These bacteria and their magnetosomes are under special attraction because of their great useful potential in nano-biotechnological and biomedical applications. MTB are ubiquitous in aquatic environments, but their isolation and axenic cultivation in pure culture is very difficult and only a limited number of them have been isolated in pure culture.

Objectives: The main goal of this study was screening, isolation and cultivation of a new strain of these fastidious bacteria in pure culture from Iran to use them and their magnetosomes.

Materials and Methods: Thirty samples were collected from various aquatic habitats. Most important physicochemical environmental factors that are involved in growth of MTB in the microcosms were investigated using inductively coupled plasma atomic emission spectroscopy (ICP-AES), portable dissolved oxygen meter, etc. Capillary racetrack technique and magnetic separation were used to purify and enrich MTB. Various isolation media were simultaneously used for isolation of a new magnetotactic bacterium in pure culture. Two imaging techniques were used to visualize the characterizations and cell division: transmission electron microscopy (TEM) and fieldemission scanning electron microscopy (FESEM). Polymerase chain reaction (PCR), ChromasPro software and MEGA5 were applied for sequence analysis of the $16 \mathrm{~S}$ rRNAgene.

Results: The results revealed a correlation of important physicochemical factors such as $\mathrm{pH}$ and iron with growth and blooms of these bacteria in the microcosms. New strain MTB-KTN90 was isolated in a modified isolation medium at microaerophilic zone from Anzali lagoon, Iran and cultured in a modified growth medium subsequently. The phylogenetic analysis showed that the strain belongs to Alphaproteobacteria. Growth and iron uptake studies indicated an important role by this bacterium in the iron biogeochemical cycle. For the first time, this paper introduced a cultured magnetotactic Alphaproteobacterium, able to synthesize magnetosomes in the temperatures above $30^{\circ} \mathrm{C}$ and reduce selenate oxyanion.

Conclusions: This paper may serve as a guide to screening, isolation, and cultivation of more new MTB. The new isolated strain opens up good opportunities for biotechnological applications such as medicine to bioremediation processes due to its unique abilities.
\end{abstract}

Keywords:Magnetic Nanoparticles; Magnetotactic Bacteria; 16S rRNA Phylogeny; Alphaproteobacteria; Anzali Lagoon

\section{Background}

Some organisms such as magnetotactic bacteria (MTB) have the ability to respond to the earth's magnetic field and use this ability for orientation purposes. For the first time, Richard P. Blakemore used the terms "magnetotaxis" and "magnetotactic bacteria" in 1975 (1-3). MTB have unique intracellular membrane-bound nanosized crystals of magnetic iron mineral called magnetosomes. They use magnetosomes for magnetic orientation in magnetic fields. Formation of magnetic nanosized particles with perfect and unique properties in magnetotactic bacteria is an interesting example of a highly controlled biomineralization process (4). Formation of magnetosomes is coupled with uptake of large amounts of extracellular iron in these bacteria. Due to their high remarkable capacity of iron minerals accumulation, it is assumed that MTB have great ecological roles in biogeochemical cycle of iron in natural habitats $(2,3)$.

Both live and dead MTB have useful potentials for medical, environmental and magnetic applications. Similar to magnetotactic bacterial cells, magnetosomes have been used in a large number of scientific, commercial and medical applications due to their useful magnetic and physical properties. The unique characteristics of magnetosomes make them ideal nanobiotechnological materials com-

Copyright ( 2014 ,Ahvaz Jundishapur University of Medical Sciences; Published by Kowsar. This is an open-access article distributed under the terms of the Creative Commons Attribution-NonCommercial 4.0 International License (http://creativecommons.org/licenses/by-nc/4.0/) which permits copy and redistribute the material just in noncommercial usages, provided the original work is properly cited. 
Tajer Mohammad Ghazvini P et al.

pared to artificial magnetic nanoparticles (3-7). Nowadays, researches in nanoparticles synthesis and assembly have turned to biological synthesis; because biosynthesis is compatible with green chemistry principles. Scientists believe that living organisms like bacteria are considered as the most potent eco-friendly nanofactories and their produced nanoparticles are more environmentally friendly and safe $(8,9)$. Therefore, isolation and cultivation of MTB in pure culture is one of the most important stages in application of these bacteria as well as magnetosomes in various biotechnological/nanotechnological fields.

MTB are ubiquitous in aquatic environments, for example freshwater swamps and ponds, rivers, lakes and marines; they are diverse according to morphology, physiology and phylogeny. Based on phylogenetic analysis, most known cultured and uncultured MTB are associated with the Alpha-, Gamma-, and Deltaproteobacteria classes of the Proteobacteria phylum and the Nitrospirae phylum. МTB live in water columns or sediments with vertical chemical concentration stratification. These bacteria situate mostly at the oxic/anoxic transition zone (OATZ) and the anoxic regions of their habitat; or both. To date, only a limited number of MTB have been isolated and grown in pure culture. Because physiology and nutritional requirements of MTB are diverse in many cases, isolation and axenic cultivation of MTB in pure culture is very difficult. Therefore, development of a general guideline has been postponed to isolation of these fastidious bacteria $(1-4,10)$.

\section{Objectives}

Isolation and characterization of MTB in pure culture can be very useful due to the great potential of these bacteria and their magnetic nanoparticles in various fields. Therefore, the purpose of this research was development of a fundamental guideline for screening, isolation and cultivation of a strain of the fastidious MTB in pure culture. This research introduced a novel isolated strain of MTB with unique characterizations such as high potential capability of iron uptake, synthesis of magnetosomes within a broad temperature range, and selenate oxyanion reduction.

\section{Materials and Methods}

\subsection{Sampling Procedures and Microcosms Setup}

Thirty samples of sediments and waters were collected during November 2010 and February, April, June, July, September 2011 from several various aquatic habitats in Iran (Neidasht spring, Selkhe Sarogh pond, Selkhe Hamzer subterranean, Zarivar lake, Soosar-Rooga river, Valasht lake, Anzali lagoon, Tonekabon river, Marzanabad recreational lake, Shirood river). The samples were transferred to glass or plastic bottles (1-2L), covered loosely, and incubated under dim light conditions at room temperature for several months (11). Sediment and water in proportion of $\sim 1: 3$ (v/v) were stored in these microcosms. The microcosms of each sampling site were collected from separate locations. The occurrence of MTB was studied in these various water-sediment microcosms over several months.

Their presence in the microcosms was determined by placing the magnetic poles of a laboratory stirring bar magnet perpendicular to the outside glass/plastic wall of the collection bottles (several centimeters above the sediment surface) (12). After 2 to 4.5 hours, a water specimen from the area close to the magnet pole was collected with a pipette and then studied by a digital light microscope and hanging drop method. Name and geographic coordinates of each microcosm are presented in Table 1. In this study, the microcosms without MTB were also enriched with $0.005 \%$ sodium succinate and $0.005 \% \mathrm{NaNO}_{3}(13)$.

Dissolved oxygen (DO) concentration was measured using a Hach HQ10 portable dissolved oxygen meter/USA. The $\mathrm{pH}$ values of water samples were determined using a Hach sensION1portable $\mathrm{pH}$ meter and the water conductivity was measured by Lovibond SensoDirect Con110 portable conductivity meter. All the measurements were in situ. The total iron concentrations of the water samples were measured by inductively coupled plasma-atomic emission spectrometry (ICP-AES).

\subsection{Capillary Racetrack Technique}

Capillary racetrack (CRT) technique was used to purify and enrich MTB after the magnetic collection from the microcosms, as described by Wolfe and colleagues (14). In this method, the narrow tip of a Pasteur pipette was sealed in a gas flame and the capillary was filled with sterilized habitat water using a syringe. A small piece of medical cotton was placed in the wide-mouth end of the pipette. The sample containing magnetically collected cells was placed on top of the sterile cotton plug in the widemouth. The filled pipette was exposed to a magnetic field produced by a magnet near the capillary end. MTB moved through the cotton plug toward the capillary end. After 30 to 90 minutes, the tip was broken off and the MTB were removed using a sterile syringe $(14,15)$.

\subsection{Optical and Electron Microscopic Analysis}

The presence of MTB was investigated by the "hanging drop" method using a digital light microscope (Motic BA310) (Spain) (1, 15). Magnetotactic responses of microorganisms in water drops were determined with a bar magnet on the optical microscope stage and recorded with a video camera (digital camera CMOS 1/2" chip). For transmission electron microscopy (TEM) study, the isolated MTB were diluted by sterilized phosphate buffer solutions (9) and then the cells were placed on the surface of carbon-coated copper grids. The bacterial cells were investigated with Philips CM30 TEM at $150 \mathrm{kV}$. Field-emission scanning electron microscopy (FESEM) images were investigated using FESEM S-4160 (Hitachi, Japan).

\subsection{Isolation Media Preparation}

After the CRT method, various and complex media were 
Tajer Mohammad Ghazvini P et al.

used for isolation experiments. The isolation media have various compounds such as different carbon or energy sources, nitrogen and iron sources (11, 16-19). The media were supplemented with Wolfe's vitamin solution, Wolfe's mineral solution (20), yeast extract, polypeptone, and filtered swamp or bog water. In the isolation process, three forms of isolation media (liquid, semi-solid and solid) were used. Sodium thioglycolate at concentrations of 50 $\mathrm{mg} / \mathrm{L}$ and neutralized cysteine- $\mathrm{HCl}$ at concentrations of 0.1 and $0.2 \mathrm{~g} / \mathrm{L}$ were used as reducing agents and resazurin was used as a redox indicator in the media. In addition, a bog water agar isolation medium was made and used for each sample in the isolation process. Cultivation was carried out under aerobic conditions, $\left[\mathrm{O}_{2}\right]:\left[\mathrm{S}^{2-}\right]$ inverse double gradient media, and anaerobic conditions. The oxygen-sulfide gradient media were composed of a plugagar which was overlaid with slush-agar(18). In this study, slush-agar was consisted of the various semi-solid isolation media, as mentioned above. Finally the screw-capped culture tubes (glass and polystyrene plastic tubes) were left loose for 24-48 hours before inoculation until sulfide and oxygen gradients were allowed to establish.

The optimal condition for isolation of strain MTB-KTN90 was a semi-solid [O2]:[S2-] inverse double gradient medium. The slush-agar (18) was optimized during this study. It contained (per $797 \mathrm{~mL}$ deionized water): $200 \mathrm{~mL}$ filtered pond water, $1 \mathrm{~mL}$ Wolfe's vitamin solution, $2 \mathrm{~mL}$ Wolfe's mineral solution, $0.05 \mathrm{~g}$ sodium succinate, $0.05 \mathrm{~g}$ yeast extract, $0.05 \mathrm{~g} \mathrm{MgSO}_{4}, 0.5 \mathrm{mM}$ potassium phosphate buffer $(\mathrm{pH}=7.0), 0.05 \mathrm{~g} \mathrm{NH}_{4} \mathrm{Cl}, 2 \mathrm{mg}$ resazurin, $20 \mu \mathrm{M}$ ferric citrate, $2 \mathrm{~g}$ agar, $0.2 \mathrm{~g}$ neutralized cysteine- $\mathrm{HCl}$, and the total $\mathrm{pH}$ was adjusted to 7.0. Sterile neutralized cysteine$\mathrm{HCl}$ and vitamin elixir were added to the slush-agar after autoclaving. The slush-agar was modified by changing the amounts of neutralized cysteine- $\mathrm{HCl}$ and ferric citrate.

\subsection{Cultivation Media Preparation for Strain MTB- KTN90}

After isolation of strain MTB-KTN90, the cells were cultured in the semi-solid growth medium (18), which was optimized during this study. The modified growth medium contained (per $1000 \mathrm{~mL}$ deionized water): $1 \mathrm{~mL}$ Wolfe's vitamin solution, $2 \mathrm{~mL}$ Wolfe's mineral solution, $0.1 \mathrm{~g}$ sodium succinate, $0.05 \mathrm{~g}$ yeast extract, $0.1 \mathrm{~g} \mathrm{MgSO}_{4}$, $1 \mathrm{mM}$ potassium phosphate buffer $(\mathrm{pH}=7.0), 0.1 \mathrm{~g} \mathrm{NH}_{4} \mathrm{Cl}$, $66.67 \mathrm{mg}$ sodium acetate anhydrous, 2 g agar, $2 \mathrm{mg}$ resazurin, $50 \mu \mathrm{M}$ ferric citrate, $0.2 \mathrm{~g}$ neutralized cysteine- $\mathrm{HCl}$, and the final pH was adjusted to 7.0. Sterile neutralized cysteine- $\mathrm{HCl}$ and vitamin elixir were added to the growth medium after the autoclaving. The growth medium was modified by adding resazurin and neutralized cysteine$\mathrm{HCl}$ and changing the quantity of ferric citrate.

\subsection{Growth and Iron Uptake Measurements}

The isolated strain was cultured microaerobically in modified liquid medium (MLM) (9) without resazurin.
The cell growth was measured spectrophotometrically at $565 \mathrm{~nm}$ (21). Estimation of the cell numbers was determined directly by a Neubauer cell-counting chamber (11). The generation time, $\mathrm{g}(\mathrm{h})$, and the division rate, $\mathrm{v}$ $\left(h^{-1}\right)$, for the exponential phase of growth were calculated from these data, using the following equations:
1) $\mathrm{n}=\log \mathrm{N}-\log \mathrm{No} / \log 2$
2) Generation time $(g)=t / n$
3) $v=1 / g$

$\mathrm{N}$ is the final cell number, No is the initial cell number, $t$ is the duration of exponential growth and $n$ is the number of generations during the period of exponential growth (22). For iron analysis, $1 \mathrm{~mL}$ of each culture sample was harvested by centrifugation (10000 rpm, 15 minutes, $4^{\circ} \mathrm{C}$ ) in a tube $1.5 \mathrm{~mL}$ (Eppendorf, Canada). Then, the supernatant was decanted, acidified with $10 \mu \mathrm{L}$ of nitric acid to $\mathrm{pH}=2.0-3.0$ (21) and analyzed by ICP-optical emission spectroscopy (Perkin Elmer Optima 7300 DV). The experiments were performed in triplicates and a cell-free culture medium was used as control.

\subsection{Other Experimental Methods}

Catalase and oxidase activities of the strain were determined by the MacFaddin standard techniques (23). Selenate reduction of the strain was determined in MLM plus $10 \mathrm{mg} / \mathrm{L}$ concentration of selenium from the filtersterilized $\mathrm{Na}_{2} \mathrm{SeO}_{4}$ stock solution (24).

\subsection{Sequence Analysis of the $16 S$ rRNA Gene}

The 16S rRNA gene of strain MTB-KTN90 was amplified, using the bacterial primers 63F (5'-CAGGCCTAACACATGCAAGTC-3') and 1389R (5'-ACGGGCGGTGTGTACAAG-3'). The oligonucleotides used as primers were synthesized and purchased from BIO BASIC Canada Inc.; the Taq DNA polymerase 2x master mix red was purchased from Ampliqon A/S, Denmark. The polymerase chain reaction (PCR) program was as follows: initial denaturation at $95^{\circ} \mathrm{C}$ for five minutes, 25 cycles of $94^{\circ} \mathrm{C}$ for 30 seconds, $70^{\circ} \mathrm{C}$ for one minute, $72^{\circ} \mathrm{C}$ for 1.5 minutes, and final elongation at $72^{\circ} \mathrm{C}$ for 10 minutes. The $16 \mathrm{~S}$ rRNA gene contiguous sequence (1231 bases) was analyzed using the ChromasPro software version 1.5 (Technelysium Pty. Ltd, http://www.technelysium.com.au).

The gene sequence was compared with the sequences in GenBank database, using the BLAST program of NCBI (http://blast.ncbi.nlm.nih.gov); the taxonomical identification was carried out by EzTaxon-e server (http://eztaxon-e. ezbiocloud.net/) (25) to obtain the nearest phylogenetic neighbors from the databases. Then, the 16S rRNA sequences of strain MTB-KTN90 and its relatives were aligned using ClustalW(26). The phylogenetic tree was constructed using MEGA5 (27) and the neighbor-joining algorithm (28, 29).

\section{Results and Discussion}

\subsection{Samples and Microcosms Experiments}

MTB normally live in aquatic environments containing water with $\mathrm{pH}$ values close to neutral to slightly-alkaline 
Tajer Mohammad Ghazvini P et al.

and dissolved iron $(1,30)$. Consistent with earlier reports, microcosms provide valuable information about the distribution and environmental studies of MTB due to the high possible resolution of sampling $(1,15)$. In this research, microcosms were used for sampling and screening strategies. After incubation in the laboratory for several months under the mentioned conditions, microcosms were stratified into aerobic and anaerobic zones, suitable for blooms of MTB. These results were consistent with previous observations by Blakemore and colleagues (11). After several months, the population of MTB remarkably increased in some of the microcosms, even without any chemical enrichment, while no MTB was observed in some of them even after chemical enrichments. In this study, MTB were determined in most of the microcosms except for the samples VALa1, SHIa2, Soosar-Rooga River, Tonekabon River, Selkhe Hamzer subterranean, and Neidasht spring. The amount of MTB was very low in VALa2, VALa3 and ANZa1, but was significantly high in other microcosms containing MTB.

Physicochemical characteristics of the samples are summarized in Table 1 . The $\mathrm{pH}$ values ranged between acidic (6.0) and alkaline (8.69). According to Table 1, $\mathrm{pH}$ could influence the growth of MTB in microcosms, because these bacteria were not detected in VALa1 ( $\mathrm{pH} 8.33$ ), Soosar-Rooga river ( $\mathrm{pH}$ 8.5-8.69), Selkhe Hamzer subterranean ( $\mathrm{pH}$ 6.0) and Neidasht spring sites ( $\mathrm{pH}$ 6.0-6.29). In addition, MTB were detected at very low numbers in VALa2 and VALa3 which might be related to their alkaline $\mathrm{pH}$ values. It has been reported that some MTB can exist in extreme environments such as high alkaline and high saline environments, which is interesting, because iron is limited due to its low solubility at high $\mathrm{pH}$ values in these environments. MTB are typically present in environments with low to moderate iron contents (0.01-1 mg/L) $(2,31)$. According to Figure 1 , the total iron concentration ranged generally from 0.01 to $0.42 \mathrm{mg} / \mathrm{L}$, except for SOOa2 ( $<0.01 \mathrm{mg} / \mathrm{L})$ and Neidasht spring sites $(<0.01 \mathrm{mg} / \mathrm{L})$. In this study, MTB were not detected in SOOa2 and Neidasht spring sites with $<0.01 \mathrm{mg} / \mathrm{L}$ total iron and Tonekabon river site ( $0.01 \mathrm{mg} / \mathrm{L}$ total iron) and they had a very low number in ANZa1 (0.01 mg/L total iron) (Figure 1). These results showed a correlation between iron and blooms of MTB. In conclusion, analysis among different microcosms originating from same habitats incubated in similar condition revealed that the environmental parameters influencing blooms of these bacteria must be very delicate.

\subsection{Isolation and Cultivation of Strain MTB-KTN90}

In this research, no magnetotactic bacterium was isolated in the liquid and solid culture media under aerobic and anaerobic conditions. Therefore, it seems that these forms of media are not very appropriate for the isolation. Finally, a novel magnetotactic bacterium (Alphaproteobacterium MTB-KTN90) was isolated and cultivated successfully in the semi-solid $\left[\mathrm{O}_{2}\right]:\left[\mathrm{S}^{2-}\right]$ inverse double gradi- ent isolation medium from Anzali lagoon in Iran during November 2011. The isolated strain grew and formed a sharp band at the microaerophilic zone in the glass screwcapped culture media tubes. Over time, with diffusion of oxygen from the tube lid as well as oxygen consumption by the bacterial cells, the bacterial band of the strain moved along the tubes until it found the optimal niche.

To date, isolation and cultivation of MTB in pure culture in laboratory has been difficult. The difficulty arises from their lifestyle, since they are fastidious and redoxsensitive. This study confirmed that the semi-solid $\mathrm{O}_{2}$ gradient media are very advantageous compared with liquid or solid media for isolation, because most MTB have microaerophilic to anaerobic lifestyles and their exact concentration of needed oxygen is unknown. These results were similar to previous investigations by Schüler and colleagues $(1,4,18)$. The results showed that cysteine$\mathrm{HCl}$ at $0.2 \mathrm{~g} / \mathrm{L}$ and glass screw-capped culture tubes were suitable for the O2-gradient media compared with the polystyrene plastic tube. In this condition, the oxygen gradients were allowed to establish very well (Figure 2).

Since oxygen could diffuse through the walls of the polystyrene plastic tubes, the glass screw-capped culture tubes compared with the polystyrene plastic tubes were useful and suitable for establishing the oxygen gradient in the semi-solid media. Adding some water from the respective aquatic habitats to the isolation media was especially important, because these bacteria live and adapt by complex patterns of vertical chemical gradients in their aquatic habitats, which are difficult to mimic under laboratory conditions (32). After using different source of iron, it was found that ferric citrate was better than others since it could be easily prepared and did not have precipitation problems (1).

\subsection{Phylogenetic Analysis}

The newly obtained 16S rRNA gene sequence was deposited in NCBI GeneBank database (www.ncbi.nlm.nih.gov) under the accession number KF623694 for Alphaproteobacterium MTB-KTN90. The phylogenetic analysis showed that the newly isolated MTB-KTN90 belongs to the class Alphaproteobacteria, phylum Proteobacteria (Figure 3). According to a sequence homology analysis of GenBank database in NCBI (with 99\% identity) and EzTaxon-e server (with 98.94\% similarity), the highest score was found with Alphaproteobacterium LM-1 which was isolated from Lake Mead in the United States (33). Based on the ruling concept, strains having 16S rRNA similarity less 97.5\% most likely belong to different species whereas 16S rRNA similarity values upper than this threshold require more investigation to determine the taxonomic status (34). The 16S rRNA gene sequence similarity of Alphaproteobacterium MTB-KTN90 was below 97.5\% to the known magnetotactic Magnetospirillum species. Alphaproteobacterium MTB-KTN90 has $90 \%$ identity to M. magnetotacticum MS-1 (35), 91\% identity to M. magneticum AMB-1 (16), and 
Tajer Mohammad Ghazvini P et al.

Table 1. Name, Location and Physicochemical Characteristics of the Microcosms ${ }^{\text {a }}$

Sampling Site and Geographic Coordinate

\begin{tabular}{|c|c|c|}
\hline \multirow[t]{5}{*}{ Neidasht spring (Mazandaran province, Iran) N $36^{\circ} 53^{\prime} 15.2^{\prime \prime}$ E 50 $34^{\prime} 26.1^{\prime \prime}$} & NEIa1 & 6.0-1.9-ND \\
\hline & NEIa2 & 6.0-1.9-ND \\
\hline & NEIb1 & 6.16-1.74-0.6 \\
\hline & NEIb2 & 6.26-1.74-0.7 \\
\hline & NEIb3 & 6.29-1.98-1.5 \\
\hline \multirow[t]{7}{*}{ Selkhe Sarogh pond (Isfahan province, Iran) N $34^{\circ} 11.0^{\prime} \mathrm{E} 51^{\circ} 15.4^{\prime}$} & SESa1 & 7.3-ND-ND \\
\hline & SESb1 & 7.01-1.18-7.0 \\
\hline & SESb2 & 7.44-1.18-6.4 \\
\hline & SESb3 & 7.40-1.11-9.2 \\
\hline & SESc1 & 7.44-1.18-6.4 \\
\hline & SESc2 & 7.44-1.18-6.4 \\
\hline & SESc3 & 7.44-1.18-6.4 \\
\hline \multirow[t]{2}{*}{ Selkhe Hamzer subterranean (Isfahan province, Iran) N $34^{\circ} 9.37^{\prime} \mathrm{E} 51^{\circ} 13.37^{\prime}$} & SEHa1 & 6.0-ND-ND \\
\hline & SEHa2 & 6.0-ND-ND \\
\hline Zarivar lake (Kurdistan province, Iran) N $35^{\circ} 32^{\prime}$ E $46^{\circ} 8^{\prime}$ & ZAR & 7.14-0.27-1.5 \\
\hline \multirow[t]{2}{*}{ Soosar-Rooga river (Gilan province, Iran) N $37^{\circ} 27.325^{\prime} \mathrm{E} 49^{\circ} 29.565^{\prime}$} & SOOa1 & $8.69-2.71-8.2$ \\
\hline & SOOa2 & $8.5-2.71-8.2$ \\
\hline \multirow[t]{3}{*}{ Valasht lake (Mazandaran province, Iran) N $36^{\circ} 32.414^{\prime}$ E $51^{\circ} 17.210^{\prime}$} & VALa1 & $8.33-0.48-8.3$ \\
\hline & VALa2 & $8.4-0.48-8.3$ \\
\hline & VALa3 & $8.3-0.48-8.3$ \\
\hline \multirow[t]{5}{*}{ Anzali lagoon (Gilan province, Iran) N $37^{\circ} 28^{\prime} 16^{\prime \prime}$ E $49^{\circ} 27^{\prime} 44^{\prime \prime}$} & ANZa1 & 8.21-2.37-3.4 \\
\hline & ANZa2 & 7.67-2.75-3.2 \\
\hline & ANZa3 & 7.18-1.46-0.4 \\
\hline & ANZa4 & 7.18-2.14-1.4 \\
\hline & ANZa5 & 7.34-2.58-3.5 \\
\hline \multirow[t]{2}{*}{ Tonekabon river (Mazandaran province, Iran) $\mathrm{N} 36^{\circ} 49.116^{\prime}$ E $50^{\circ} 52.793^{\prime}$} & TONa1 & $7.39-0.18-6.5$ \\
\hline & TONa2 & $7.5-0.18-6.5$ \\
\hline 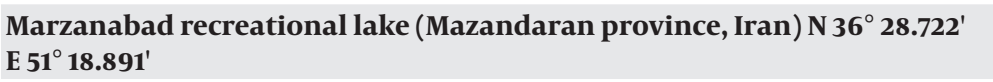 & MAR & $6.95-0.19-7.4$ \\
\hline \multirow[t]{2}{*}{ Shirood river (Mazandaran province, Iran) N $36^{\circ} 50.524^{\prime}$ E $50^{\circ} 47.953^{\prime}$} & SHIa1 & 6.9-0.04-9.3 \\
\hline & SHIa2 & $6.7-0.04-9.3$ \\
\hline
\end{tabular}

a Abbreviations: ND, not determined; EC, Electrical conductivity; DO, Dissolved oxygen.

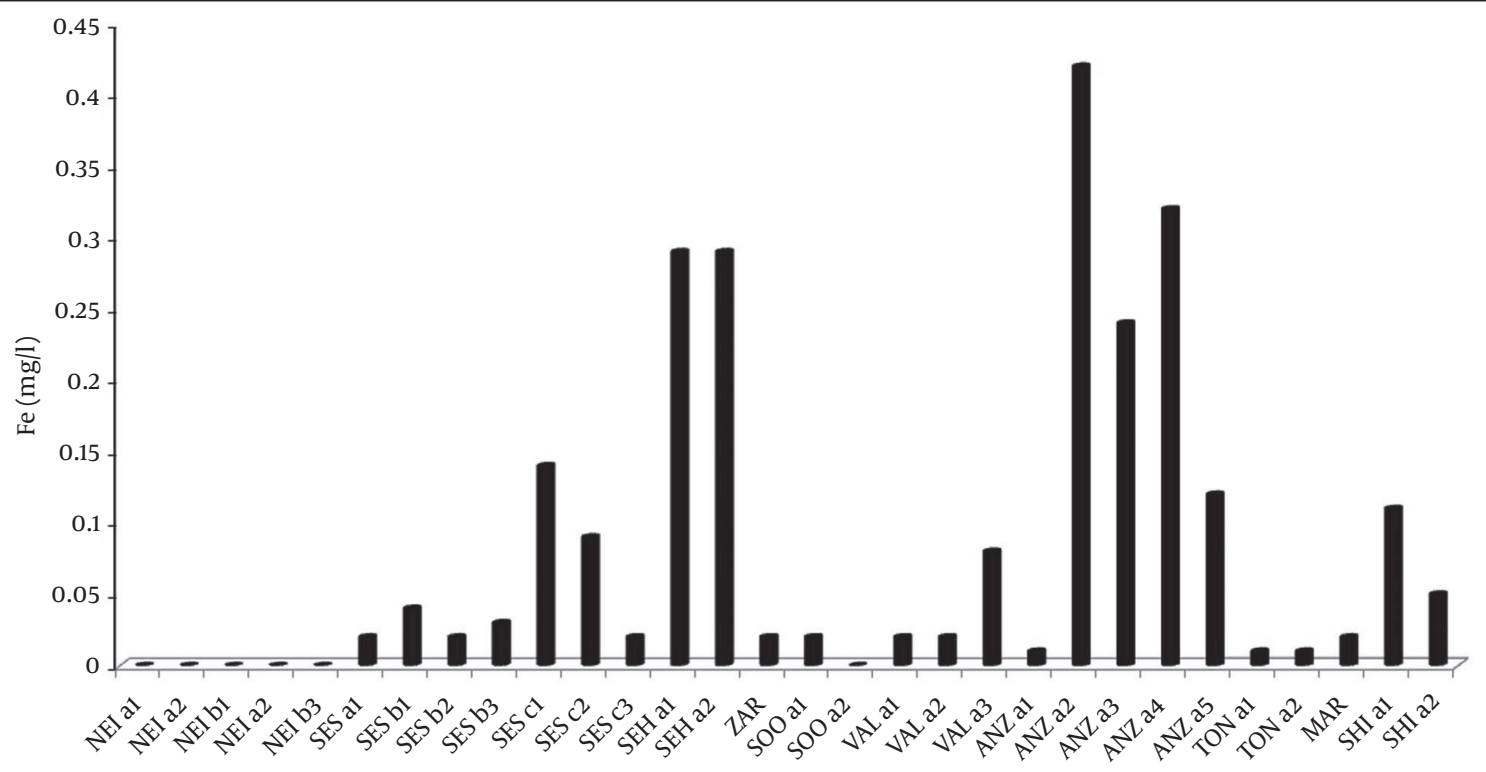

Name of the Microcosms

Figure 1. Total Iron Concentrations of Water Collected From the Microcosms 
90\% identity to M. gryphiswaldense MSR-1 (36). Therefore, Alphaproteobacterium MTB-KTN90 represents different species from the known magnetotactic Magnetospirillum species. The phylogenetic tree based on the 16S rRNA gene showed the relationship between the newly isolated MTBKTN90 and other related bacteria (Figure 3).

\subsection{Characteristics of Strain MTB-KTN90}

Strain MTB-KTN90 is a Gram-negative bacterium. The cells are motile using a single polar flagellum. TEM observations (Figure 4) showed that the cells morphology was vibrioid to helical form with $0.15-0.5 \mu \mathrm{m}$ width and 1.5-2.0 $\mu \mathrm{m}$ length. The magnetosome chain arrangement is also presented in Figure 4. Previous studies suggested that the magnetosome chain was cleaved and divided between the daughter cells during cell division in magnetotactic bacteria (39), as represented by Figures 5 and $6 \mathrm{~B}$. Figures 5 and 6 show the strain cells during the cellular division. FESEM and TEM micrographs of MTB-KTN90 cells revealed that they had asymmetric division (Figure 6). The cells spilt by unidirectional indentation, which is similar to asymmetric division in M. gryphiswaldense. This novel snapping mechanism in magnetotactic bacteria is assumed to overcome the magnetic force generated by the magnetosome chain structure (40).

Figure 7 shows the growth and iron uptake of MTBKTN90. According to Figure 7 and Table 2, a link between the iron uptake and growth was evaluated in this strain. The biomass increase was correlated with iron uptake. The dissolved iron concentration had a sharp decrease in the exponential growth phase, while in the stationary phase, it had a slight decrease and iron uptake continued slowly thereafter. In this condition, the strain absorbed $2.17 \mathrm{mg} / \mathrm{L}$ iron at $7.19 \mathrm{mg} / \mathrm{L}$ initial iron concentration. The bacterial cells absorbed about $30.18 \%$ of the dissolved iron from the growth medium, which was equal to $3.87 \%$ of the dry weight. According to previous studies, MTB have had the ability to uptake vast amounts of iron from the environment (up to $4 \%$ of the dry weight), which was coupled to their formation of magnetosomes; while, the total iron content in Escherichia coli has been $0.005-0.022 \%$ of the dry weight. These findings suggested the significant contribution of MTB to the biogeochemical cycling of iron. It is estimated that they have contribution to the flux of iron to sediments; however, this contribution to iron cycling in the environments still has to be addressed quantitatively $(2,41)$.

In preliminary experiments, MTB-KTN90 was able to tolerate and reduce selenate oxyanion under microaerobic conditions. Selenate reduction is a valuable capability for this strain, which has not been reported in other magnetotactic bacteria so far. Bacterial reduction of selenate is an important biogeochemical process in an aquatic environment. Today, selenium pollution is worldwide and is associated with human activities. Oxyanion forms of selenium are toxic to living organisms and bacteria; but, some microorganisms such as bacteria can apply their metabolic capacity in different ways to transform the oxyanions to other nontoxic chemicals. Nowadays, removal of toxic selenium compounds from wastewater before discharge is becoming increasingly imperative in industrialized countries $(24,42)$. Application of MTB in bioremediation processes has a promising future (6); therefore, this strain is an interesting finding and a promising opportunity for bioremediation in natural environments.

Figure 2. The Glass Screw-Capped Culture Tube Including Semi-Solid $\left[\mathrm{O}_{2}\right]:\left[\mathrm{S}^{2-}\right]$ Inverse Double Gradient Medium

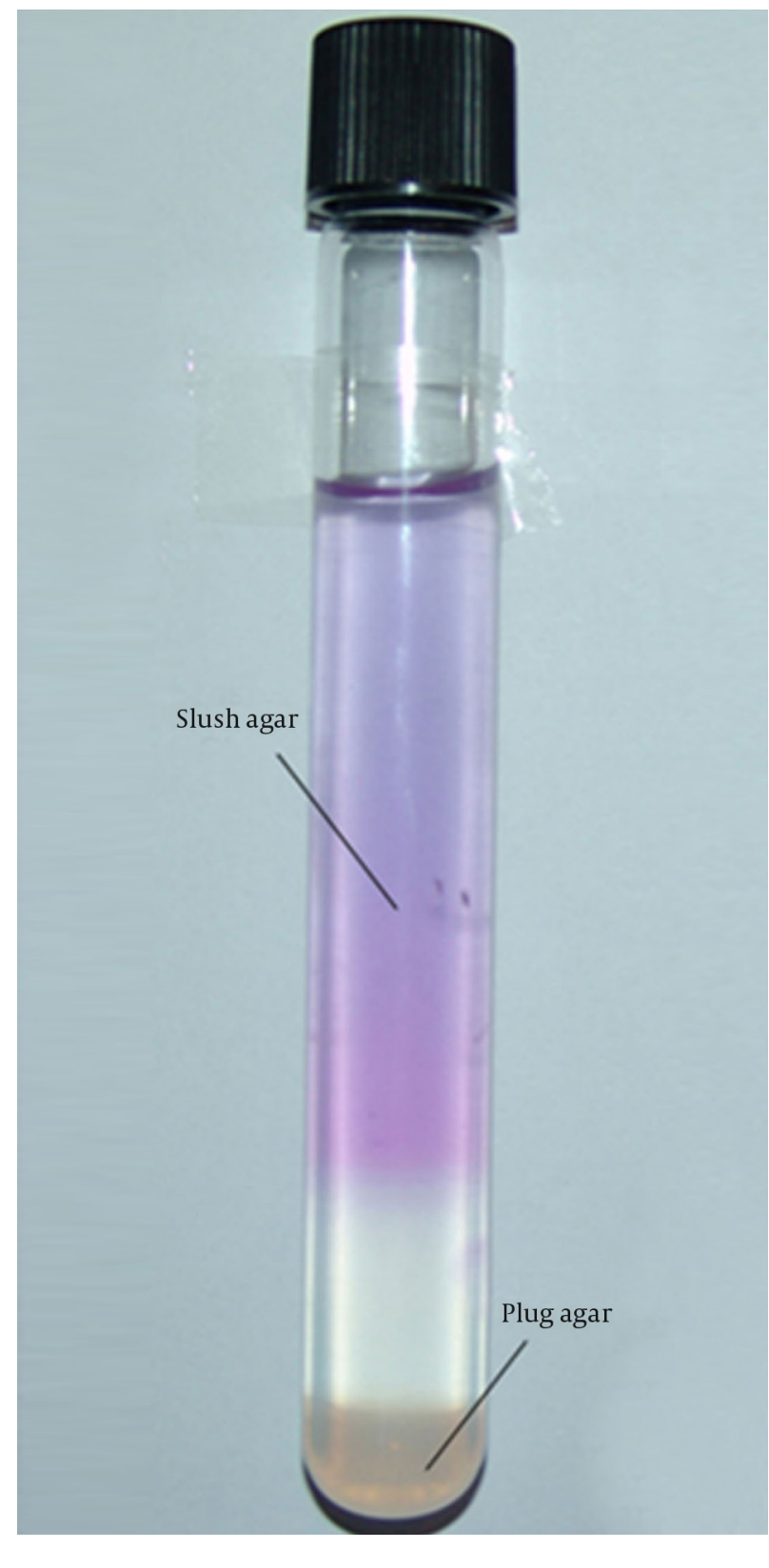

The Redox Indicator (Resazurin) Allows Visualization of $\mathrm{O}_{2}$-Gradient in the Medium Which Is Colorless When Fully Reduced. 
Figure 3. The Phylogenetic Tree Based on the 16S rRNA Gene Sequences, Showing the Phylogenetic Position of the Newly Isolated Alphaproteobacterium MTB-KTN90

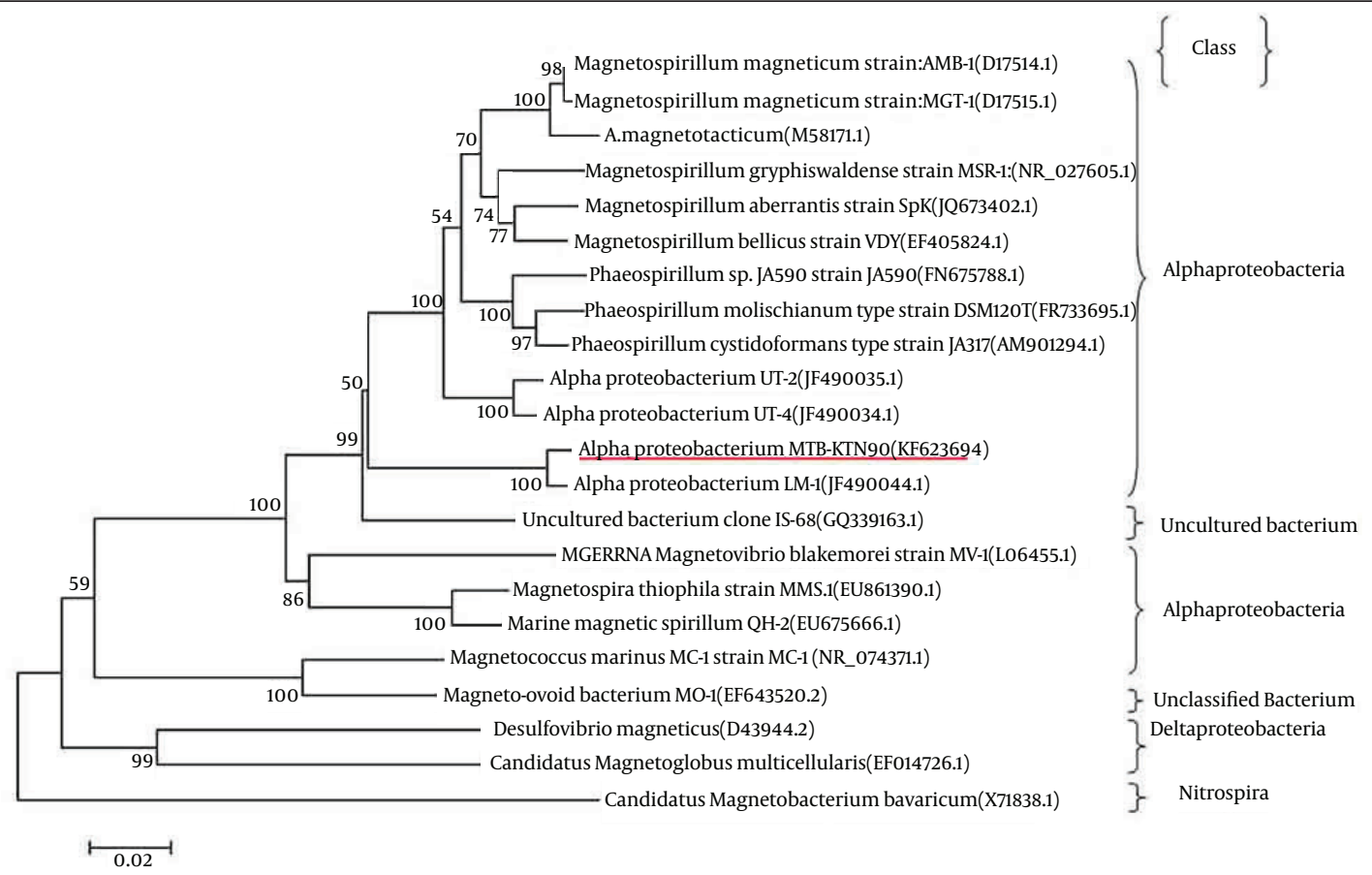

The result was evaluated by bootstrap analysis based on 1000 replicates (37). Candidatus Magnetobacterium bavaricum (phylum Nitrospirae)(38) was taken as an out-group. The GenBank accession numbers are indicated after the names in parentheses.Alphaproteobacterium MTB-KTN90 is indicated by underline

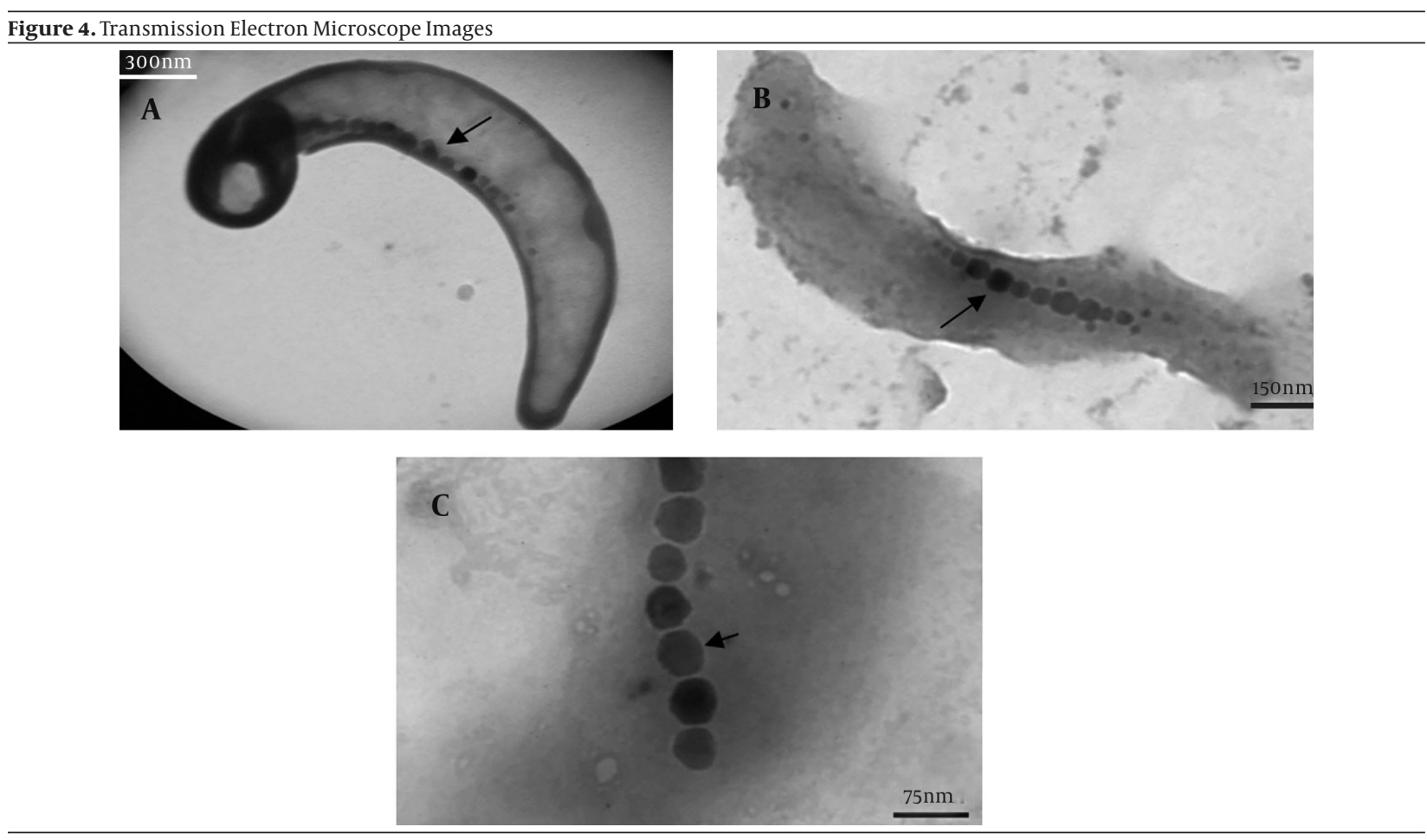

(a,b) TEM image of magnetotactic strain MTB-KTN90, arrow $(\rightarrow$ ) shows the chain of magnetosomes (c) TEM image of the magnetosomes chain inside the bacterium, arrow $(\rightarrow)$ shows the coated magnetic nanoparticles with a natural thin membrane. The membrane is seen as a clear zone around the nanoparticles. 
Figure 5. Transmission Electron Microscope Images of Strain MTB-KTN90 During Cellular Division.
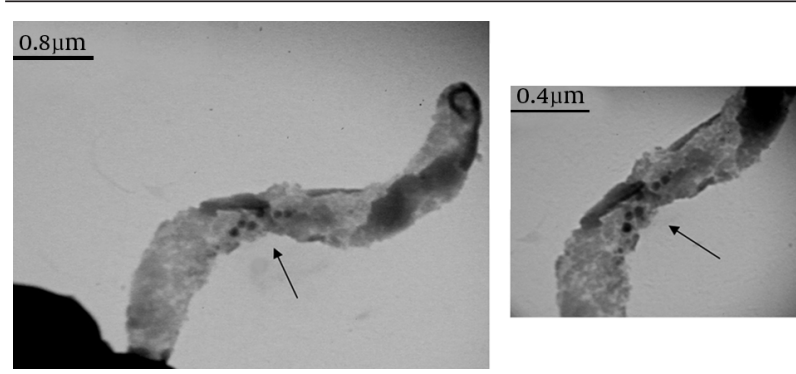

Arrows $(\rightarrow)$ indicate the cell and magnetosome chain division positions.
Figure 6. Field-Emission Scanning Electron Microscope and Transmission Electron Microscope Micrographs of Alphaproteobacterium MTB-KTN90
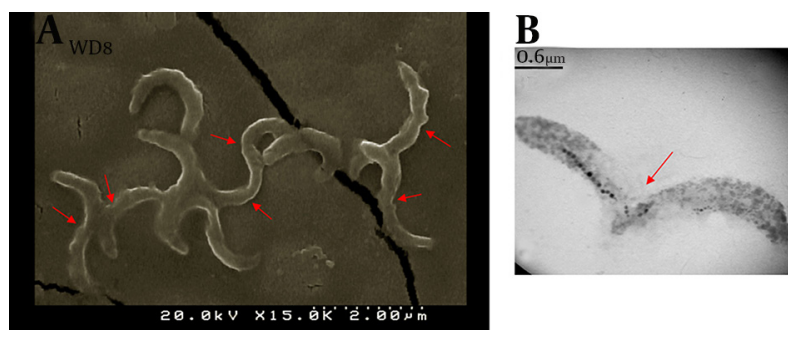

(a) Field-Emission scanning electron microscope and (b) transmission electron microscope micrographs of Alphaproteobacterium MTB-KTN90 during cell division. Arrows $(\rightarrow)$ indicate the cell and magnetosome chain division positions.

Figure 7. Growth and Iron Uptake of MTB-KTN90
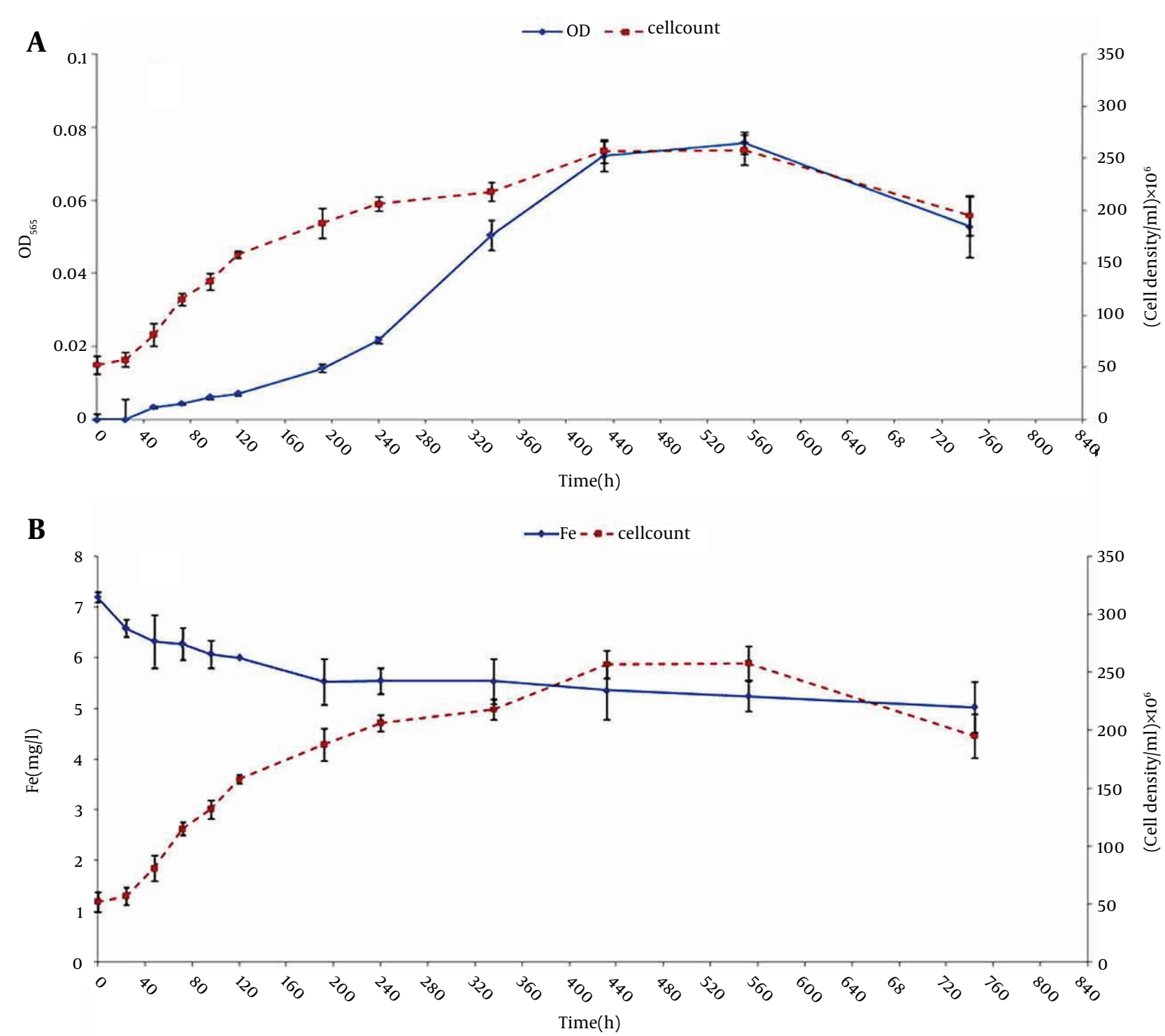

(a) $\Delta$ OD565 and Cell Count (b) Iron Uptake and Cell Count of Alphaproteobacterium MTB-KTN90 During Microaerobic Cultivation in Modified Liquid Medium. 
Tajer Mohammad Ghazvini P et al.

\begin{tabular}{|c|c|c|c|c|c|}
\hline Microorganism & Generation Time, $h$ & Division Rate, $\mathbf{h}^{-1}$ & $\begin{array}{l}\text { Medium Iron Concentration } \\
\text { Before the Growth, } \mathrm{mg} / \mathrm{L}\end{array}$ & $\begin{array}{l}\text { Medium Iron Concentration } \\
\text { After the Growth, } \mathrm{mg} / \mathrm{L}\end{array}$ & $\begin{array}{c}\text { Iron, mg/L/Biomass } \\
\text { Dry Weight, mg }\end{array}$ \\
\hline $\begin{array}{l}\text { Alphaproteobacterium } \\
\text { MTB-KTN90 }\end{array}$ & 68.3 & 0.015 & $7.2 \pm 0.1$ & $5.02 \pm 0.4$ & 3.57 \\
\hline
\end{tabular}

Catalase and oxidase activities were not detected in MTB-KTN90. The results indicated that the mesophilic strain MTB-KTN90 could grow well and synthesize the magnetosomes in temperatures above $30^{\circ} \mathrm{C}$, up to $40^{\circ} \mathrm{C}$. The newly isolated strain was the first report of cultured MTB belonging to the class Alphaproteobacteria which is able to grow well and synthesize the magnetosomes in temperatures above $30^{\circ} \mathrm{C}$, up to $40^{\circ} \mathrm{C}$, while most known cultured MTB and also all cultured magnetotactic Alphaproteobacteria are mesophile and do not grow much above $30^{\circ} \mathrm{C}$ (e.g, Magnetospirillum species and D. magneticus, strains MV-1 and MC-1) $(4,43)$. The unique stress tolerance property of this magnetotactic strain has a great potential for biotechnological and medical applications. It is evident that pure culture of magnetotactic bacteria in defined medium has provided effective advancements on application of these bacteria and their unique intracellular magnetic nanoparticles. Researches in this field are greatly remarkable because of great potential of these bacteria and their magnetosomes in various biotechnological and nanotechnological fields. This research introduced a new magnetotactic bacterium with unique characteristics. Alphaproteobacterium MTB-KTN90 is a mesophilic cultured Alphaproteobacterium that can grow well and synthesize intracellular magnetic nanoparticles over $30^{\circ} \mathrm{C}$, which is unusual among all cultured magnetotactic Alphaproteobacteria. The results also demonstrated the high capability of MTB-KTN90 for iron uptake. These findings suggested the significant contribution of MTBKTN90 in the biogeochemical cycling of iron in natural aquatic habitats. Furthermore, the isolated strain showed an interesting potential capability in removing the toxic selenium compounds from natural environments.

This paper may serve as a guide for isolation and cultivation of other new strains of magnetotactic bacteria. Since a few magnetotactic bacteria have been available in pure culture so far, the novel strain MTB-KTN90 could be an especially useful model in various fields. Therefore, the strain is a suitable candidate for biotechnological applications such as medicine (drug delivery, magnetic resonance imaging (MRI), etc.) as well as bioremediation processes, due to its unique abilities.

\section{Acknowledgements}

The authors are grateful to Saeid Ghorbanzadeh-Mashkani and Dr. Reza Dabbagh for their valuable contributions to this project. We also thank Masoud Ghorbanzadeh-Mashkani for his help in the sampling and Dr. Roohollah Nakhaei-Sistani for his help in the phylogenetic analysis.

\section{Authors' Contributions}

This manuscript was a part of the Ph.D. thesis by P. TajerMohammad-Ghazvini, under the supervision of Dr. R. Kasra-Kermanshahi and Dr. A. Nozad-Golikand; and advisory of Dr. M. Sadeghizadeh.

\section{Funding/Support}

This study was a part of the Ph.D. thesis, Alzahra University, Tehran, IR Iran.

\section{References}

1. Schüler D. Magnetoreception and Magnetosomes in Bacteria.: Springer-Verlag Berlin Heidelberg; 2007.

2. Faivre D, Schüler D. Magnetotactic bacteria and magnetosomes. Chem Rev. 2008;108(11):4875-98.

3. Yan L, Zhang S, Chen P, Liu H, Yin H, Li H. Magnetotactic bacteria, magnetosomes and their application. Microbiol Res. 2012;167(9):507-19.

4. Bazylinski DA, Lefèvre CT, Schüler D. Magnetotactic Bacteria. In: Rosenberg E, DeLong EF, Lory S, Stackebrandt E, Thompson F editors. The Prokaryotes.: Springer Berlin Heidelberg; 2013. pp. 453-94.

5. Matsunaga T, Suzuki T, Tanaka M, Arakaki A. Molecular analysis of magnetotactic bacteria and development of functional bacterial magnetic particles for nano-biotechnology. Trends Biotechnol. 2007;25(4):182-8.

6. Zhou W, Zhang Y, Ding X, Liu Y, Shen F, Zhang X, et al. Magnetotactic bacteria: promising biosorbents for heavy metals. Appl Microbiol Biotechnol. 2012;95(5):1097-104.

7. Ghorbanzadeh-Mashkani S, Tajer-Mohammad-Ghazvini P, Nozad-Golikand A, Kasra-Kermanshahi R, Davarpanah M. Synthesis of sterile and pyrogen free biogenic magnetic nanoparticles: biotechnological potential of magnetotactic bacteria for production of nanomaterials. World Academy of Science, Engineering and Technology, International Science Index 74. 2013;7:687-91.

8. Arya V. Living systems: eco-friendly nanofactories. Dig J Nanomater Bios. 2010;5:9-21.

9. Tajer-Mohammad-Ghazvini P, Kasra-Kermanshahi R, Nozad-Golikand A, Sadeghizadeh M. A green chemical technique for the synthesis of magnetic nanoparticles by magnetotactic bacteria. World Academy of Science, Engineering and Technology, International Science Index 74. 2013;7:683-6.

10. Lin W, Bazylinski DA, Xiao T, Wu L-F, Pan Y. Life with compass: diversity and biogeography of magnetotactic bacteria. Environ Microbiol. 2013:n/a.

11. Blakemore RP, Maratea D, Wolfe RS. Isolation and pure culture of a freshwater magnetic spirillum in chemically defined medium. J Bacteriol. 1979;140(2):720-9.

12. Moench TT, Konetzka WA. A novel method for the Isolation and Study of a magnetotactic bacterium. Arch Microbiol. 1978;119(2):203-12.

13. Matsunaga T, Kamiya S. Use of magnetic particles isolated from magnetotactic bacteria for enzyme immobilization. Appl Microbiol Biotechnol.1987;26(4):328-32.

14. Wolfe RS, Thauer RK, Pfennig N. A capillary racetrack method for isolation of magnetotactic bacteria. FEMS Microbiol Ecol. 1987;45(1):31-5.

15. Flies CB, Peplies J, Schüler D. Combined approach for characterization of uncultivated magnetotactic bacteria from various aquatic environments. Appl Environ Microbiol. 2005;71(5):2723-31.

16. Matsunaga T, Sakaguchi T, Tadokoro F. Magnetite formation by a 
magnetic bacterium capable of growing aerobically. Appl Microbiol Biotechnol. 1991;35(5):651-5.

17. Sakaguchi T, Tsujimura N, Matsunaga T. A novel method for isolation of magnetic bacteria without magnetic collection using magnetotaxis. J Microbiol Methods. 1996;26(1-2):139-45.

18. Schüler D, Spring S, Bazylinski DA. Improved technique for isolation of magnetotactic spririlla from a freshwater sediment and their phylogenetic characterization. System Appl Microbiol. 1999;22(3):466-71.

19. Atlas RM. Handbook of media for environmental microbiology. 2 ed: CRC Press, Taylor \& Francis Group; 2005.

20. Wolin EA, Wolin MJ, Wolfe RS. Formation of methane by bacterial extracts.J Biol Chem. 1963;238:2882-6.

21. Heyen U, Schüler D. Growth and magnetosome formation by microaerophilic Magnetospirillum strains in an oxygen-controlled fermentor. Appl Microbiol Biotechnol. 2003;61(5-6):536-44.

22. Madigan MT, Stahl D, Martinko JM. Brock Biology of Microorganisms. 13 ed: Benjamin Cummings; 2011.

23. MacFaddin J. Biochemical tests for identification of medical bacteria. 2 ed: The Williams \& Wilkins Co., Baltimore/London; 1980 .

24. Soudi MR, Tajer Mohammad Ghazvini P, Khajeh K, Gharavi S. Bioprocessing of seleno-oxyanions and tellurite in a novel Bacillus sp. strain STG-83: A solution to removal of toxic oxyanions in presence of nitrate. J Hazard Mater. 2009;165(1-3):71-7.

25. Kim OS, Cho YJ, Lee K, Yoon SH, Kim M, Na H, et al. Introducing EzTaxon-e: a prokaryotic 16S rRNA Gene sequence database with phylotypes that represent uncultured species. Int J Syst Evol Microbiol. 2012;62(Pt 3):716-721.

26. Thompson JD, Higgins DG, Gibson TJ. CLUSTAL W: improving the sensitivity of progressive multiple sequence alignment through sequence weighting, position-specific gap penalties and weight matrix choice. Nucleic Acids Res. 1994;22(22):4673-80.

27. Tamura K, Peterson D, Peterson N, Stecher G, Nei M, Kumar S. MEGA5: molecular evolutionary genetics analysis using maximum likelihood, evolutionary distance, and maximum parsimony methods. Mol Biol Evol. 2011;28(10):2731-9.

28. Saitou N, Nei M. The neighbor-joining method: a new method for reconstructing phylogenetic trees. Mol Biol Evol. 1987; 4(4):406-25.

29. Tamura K, Nei M, Kumar S. Prospects for inferring very large phylogenies by using the neighbor-joining method. Proc Natl Acad Sci US A. 2004;101(30):11030-5.

30. Bazylinski DA, Frankel RB. Biologically controlled mineralization in prokaryotes. Rev Mineral Geochem. 2003;54:217-47.

31. Lefèvre CT, Frankel RB, Pósfai M, Prozorov T, Bazylinski DA. Isolation of obligately alkaliphilic magnetotactic bacteria from extremely alkaline environments. Environ Microbiol. 2011;13(8):2342-50.

32. Spring S, Bazylinski DA. Magnetotactic Bacteria. In: Dworkin M Falkow S, Rosenberg E, Schleifer K-H, Stackebrandt E editors. The Prokaryotes. 3 ed: Springer; 2006. pp. 842-62.

33. Lefèvre CT, Schmidt ML, Viloria N, Trubitsyn D, Schüler D, Bazylinski DA. Insight into the Evolution of Magnetotaxis in Magnetospirillum spp., Based on mam Gene Phylogeny. Appl Environ Microbiol. 2012;78(20):7238-48.

34. Li W, Yu L, Zhou P, Zhu M. A Magnetospirillum strain WM-1 from a freshwater sediment with intracellular magnetosomes. World $J$ Microbiol Biotechnol. 2007;23(10):1489-92.

35. Maratea D, Blakemore RP. Aquaspirillum magnetotacticum sp. nov., a magnetic spirillum. Int J Sys Bacteriol. 1981;31(4):452-5.

36. Schleifer KH, Schüler D, Spring S, Weizenegger M, Amann R, Ludwig W, et al. The genus Magnetospirillum gen. nov. Description of Magnetospirillum gryphiswaldense sp. nov. and transfer of Aquaspirillum magnetotacticum to Magnetospirillum magnetotacticum comb. nov. System Appl Microbiol. 1991;14(4):379-85.

37. Felsenstein J. Confidence limits on phylogenies: An approach using the bootstrap. Evolution. 1985;39:783-91.

38. Spring S, Amann R, Ludwig W, Schleifer KH, Gemerden HV, Petersen $N$. Dominating role of an unusual magnetotactic bacterium in the microaerobic zone of a freshwater sediment. Appl Environ Microbiol. 1993;59(8):2397-403.

39. Greene SE, Komeili A. Biogenesis and subcellular organization of the magnetosome organelles of magnetotactic bacteria. Curr Opin Cell Bio. 2012;24(4):490-5.

40. Lin W, Pan Y. Snapping magnetosome chains by asymmetric cell division in magnetotactic bacteria. Mol Microbiol. 2011;82(6):1301-4.

41. Schüler D, Baeuerlein E. Iron-limited growth and kinetics of iron uptake in Magnetospirillum gryphiswaldense. Arch Microbiol. 1996;166(5):301-7.

42. Hageman SPW, van der Weijden R, Weijma J, Buisman CJN. Microbiological selenate to selenite conversion for selenium removal. Water Res. 2013;47(7):2118-28.

43. Lefèvre CT, Abreu F, Schmidt ML, Lins U, Frankel RB, Hedlund BP, et al. Moderately thermophilic magnetotactic bacteria from hot springs in Nevada. . Appl Environ Microbiol. 2010;76(11):3740-3. 